\title{
Hospital volume and other risk factors for in-hospital mortality among diverticulitis patients: A nationwide analysis
}

\author{
Michael J Diamant MD MSc ${ }^{1}$, Stephanie Coward $\mathrm{MSc}^{1,2}, \mathrm{~W}$ Donald Buie MD ${ }^{3}$, Anthony MacLean MD ${ }^{3}$, \\ Elijah Dixon MD MSc ${ }^{3}$, Chad G Ball MD³, Samuel Schaffer MD ${ }^{4}$, Gilaad G Kaplan MD MPH ${ }^{1,2}$
}

MJ Diamant, S Coward, WD Buie, et al. Hospital volume and other risk factors for in-hospital mortality among diverticulitis patients: A nationwide analysis. Can J Gastroenterol Hepatol 2015;29(4):193-197.

BACKGROUND: Previous studies have found that a higher volume of colorectal surgery was associated with lower mortality rates. While diverticulitis is an increasingly common condition, the effect of hospital volume on outcomes among diverticulitis patients is unknown.

OBJECTIVE: To evaluate the relationship between hospital volume and other factors on in-hospital mortality among patients admitted for diverticulitis.

METHODS: Data from the Nationwide Inpatient Sample (years 1993 to 2008) were analyzed to identify 822,865 patients representing $4,108,726$ admissions for diverticulitis. Hospitals were divided into quartiles based on the volume of diverticulitis cases admitted over the study period, adjusted for years contributed to the dataset. Mortality according to hospital volume was modelled using logistic regression adjusting for age, sex, race, comorbidities, health care insurance, admission type, calendar year, colectomy, disease severity and clustering. Risk estimates were expressed as adjusted ORs with 95\% CIs.

RESULTS: Patients at high-volume hospitals were more likely to be admitted emergently, undergo surgical treatment and have more severe disease. In-hospital mortality was higher among the lowest quartile of hospital volume compared with the highest volume (OR 1.13 [95\% CI 1.05 to 1.21]). In-hospital mortality was increased among patients admitted emergently (OR 2.58 [95\% CI 2.40 to 2.78]) as well as those receiving surgical treatment (OR 3.60 [95\% CI 3.42 to 3.78]).

CONCLUSIONS: Diverticulitis patients admitted to hospitals with a low volume of diverticulitis cases had an increased risk for death compared with those admitted to high-volume centres.

Key Words: Colectomy; Diverticulitis; Hospital volume; Mortality

\section{Le volume hospitalier et d'autres facteurs de risque de mortalité hospitalière chez les patients atteints de diverticulite : une analyse nationale}

HISTORIQUE : Des études antérieures ont établi qu'un plus fort volume de chirurgie colorectale s'associait à une diminution du taux de mortalité. La diverticulite est de plus en plus fréquente, mais on ne connaît pas l'effet du volume hospitalier sur l'issue des patients qui en sont atteints.

OBJECTIF : Évaluer le lien entre le volume hospitalier et d'autres facteurs sur la mortalité hospitalière des patients hospitalisés en raison d'une diverticulite.

MÉTHODOLOGIE : Les chercheurs ont analysé les données du Nationwide Inpatient Sample (1993 à 2008) pour en extraire 822865 patients représentant 4108726 hospitalisations en raison d'une diverticulite. Ils ont réparti les hôpitaux en quartiles selon le volume de cas de diverticulite admis pendant la période de l'étude, rajusté compte tenu des années de participation au fichier de données. Ils ont établi le modèle de mortalité selon le volume hospitalier au moyen de la régression logistique rajustée en fonction de l'âge, du sexe, de la race, des comorbidités, de l'assurancemaladie, du type d'admission, de l'année civile, de la colectomie, de la gravité de la maladie et des regroupements. Ils ont exprimé le risque sous forme de rapport de cote (RC) rajusté ayant un indice de confiance de $95 \%$.

RÉSULTATS : Les patients des hôpitaux à fort volume étaient plus susceptibles d'être admis en urgence, de subir un traitement chirurgical et d'avoir une maladie plus grave. La mortalité hospitalière était plus élevée dans le plus petit quartile de volume hospitalier que dans celui ayant le volume le plus élevé (RC 1,13 [95 \% IC 1,05 à 1,21]). La mortalité hospitalière était plus élevée chez les patients admis d'urgence (RC 2,58 [95 \% IC 2,40 à 2,78]) et chez ceux ayant subi un traitement chirurgical (RC 3,60 [95 \% IC 3,42 à 3,78]).

CONCLUSIONS : Les patients atteints de diverticulite admis dans des hôpitaux ayant un faible volume de cas de diverticulite présentaient un risque de décès plus élevé que ceux qui étaient admis dans des centres à fort volume.

oral or intravenous antibiotics in cases of diverticulitis without the above complications (7). Percutaneous drainage, in conjunction with intravenous antibiotics, is the treatment of choice in patients with large diverticular abscesses $(7,8)$. Between $10 \%$ and $45 \%$ of patients who develop diverticulitis will undergo surgical management $(9,10)$, with approximately $25 \%$ of patients requiring surgery during their initial hospital admission for diverticulitis (10).

Previous studies have found lower mortality rates at high-volume hospitals during hospitalization or postoperatively for patients with inflammatory bowel disease (11-13). On the other hand, Karanicolas et al (14) examined the effects of both surgeon and hospital volumes on mortality from colorectal resection for various reasons, and found that while surgeons seeing a higher-volume caseload was associated with a n the United States, diverticular disease accounted for approxi-
mately 314,000 hospitalizations in 2006 (1), while in 2005 , the
age-adjusted hospitalization rate for diverticulitis was 75.5 per 100,000
persons (2). Diverticulitis develops in $10 \%$ to $25 \%$ of patients with
diverticulosis (3), and is more common in elderly individuals (4). The
severity of diverticulitis spans from mild (controlled by conservative
medical management) to life-threatening (requiring surgical interven-
tion) (5). Approximately $15 \%$ to $20 \%$ of patients with diverticulitis
will develop complications such as abscess or fistula formation,
obstruction, bleeding or perforation ( 3,6 ).
Consequently, management of diverticulitis depends on the sever-
ity of the disease, with established guidelines recommending non-
operative treatment with dietary modification and administration of

${ }^{1}$ Departments of Medicine; ${ }^{2}$ Community Health Sciences; and ${ }^{3}$ Surgery, University of Calgary, Calgary, Alberta; ${ }^{4}$ Global Medical Affairs, Shire Canada,

Toronto, Ontario

Correspondence: Dr Gilaad G Kaplan, Departments of Medicine and Community Health Sciences, University of Calgary, 6D17,

3280 Hospital Drive Northwest, Calgary, Alberta T2N 4N1. Telephone 403-592-5015, fax 403-592-5050, e-mail ggkaplan@ucalgary.ca

Received for publication September 14, 2014. Accepted January 12, 2015 
lower mortality rate, an association between hospital volume and mortality rates was not observed. Furthermore, Weber et al (15) found that diverticulosis and diverticulitis patients undergoing sigmoid colon resection were more likely to receive laparoscopic versus open sigmoid colectomies in high-volume hospitals, although a difference in mortality between the two types of surgery was not demonstrated (16). Thus, the effect of hospital volume on mortality related to surgical and medical management of diverticulitis remains unknown.

The objectives of the present study were to use a nationally representative database of hospital discharges in the United States to determine the effect of hospital volume on mortality for all inpatients with diverticulitis, as well as to evaluate other risk factors for mortality on patients hospitalized for diverticulitis.

\section{METHODS \\ Study design and patient population}

The Nationwide Inpatient Sample (NIS) is a collection of inpatient records from a cross-section of 1000 acute care hospitals across the United States (US) representing approximately eight million admissions per year, which provides a $20 \%$ stratified sample of US hospitals. The database is populated using stratified random sampling to ensure it accounts for approximately $90 \%$ of hospital admissions and is representative of the US population. The NIS contains deidentified demographic information, diagnostic and procedure codes based on the International Classification of Diseases, Ninth Revision, Clinical Modification (ICD-9-CM), outcomes, and hospital characteristics. The NIS is compiled and validated by the Agency for Healthcare and Research Quality (Rockville, Maryland, USA).

\section{Data collection and outcomes}

ICD-9-CM codes $(562.01,562.03,562.11$ or 562.13$)$ were used to identify 822,865 patients admitted with diverticulitis in all diagnostic positions from 1993 to 2008. Patients who underwent surgery for their diverticulitis were identified with the following ICD-9-CM codes: 45.71, 45.72, 45.73, 45.74, 45.75, 45.76, 45.79, 45.8, 45.81, 45.82 and 45.83. Patients with colostomies (codes 46.1, 46.11, 46.13) and ileostomies (46.2, 46.20, 46.21, 46.22, 46.23, 46.24) were excluded from the surgery group because the vast majority (>99\%) did not have concurrent coding of resection operations during admission. Additionally, all patients were stratified according to disease severity as defined by the Hinchey classification (17), which categorizes diverticulitis according to an assessment of peritoneal contamination. Patients with ICD-9-CM codes 567.22, 569.5 and 614.3 reflecting the presence of a pericolic, mesenteric or walled-off pelvic abscess were identified as Hinchey I or II. Patients with ICD9-CM codes 567, 567.21, 567.9 and 614.5 reflecting the presence of either generalized purulent or fecal peritonitis were identified as Hinchey III or IV.

The primary comparison of interest was hospital volume, which was determined by dividing the hospitals into quartiles based on the total number of diverticulitis patients admitted over the total study period. The variable number of years each hospital contributed to the dataset was taken into account. The median number of diverticulitis admissions at a single hospital was 440 (interquartile range 216 to 793 ). The primary outcome of interest in the present study was in-hospital mortality.

\section{Statistical analysis}

Descriptive statistics with Wald confidence limits, with NIS sample weights taken into account, were used to summarize patient characteristics in each quartile of hospital volume. A complete case analysis was used for the comparison of all patient characteristics, covariates and outcomes.

All risk estimates are represented by adjusted ORs created using logistic regression with a marginal generalized estimating equation extension. The generalized estimating equations account for clustering of responses by hospital (ie, to account for the potential correlation of outcomes between patients from the same hospital). The sampling weights for each observation were included in all analyses. For all multivariable analyses, the following variables were included as covariates: age, categorized as $<40,40$ to 64 and $\geq 65$ years of age; sex; race and ethnicity classified as non-Hispanic white, black, Hispanic and other/ unavailable (because multiple states purposely do not collect information on race); comorbidity index scores, which were based on the presence of 30 illnesses and modelled continuously (18); health insurance status, classified as Medicare, Medicaid, private insurance, self-pay or other; admission type, classified as elective, urgent (which requires immediate attention for care or treatment) or emergent (which denotes medical intervention required as a result of severe, potentially fatal or disabling conditions); disease severity determined by ICD-9 codes reflecting Hinchey classification, categorized as no Hinchey score, Hinchey I or II, and Hinchey III or IV; calendar year of admission, modelled as a continuous variable; and whether the patient underwent a colectomy as surgical treatment. A sensitivity analysis was performed in which only patients who had diverticulitis as the primary diagnosis on admission were included in the analysis.

All analyses were performed using SAS version 9.2 (SAS Institute, USA); associations with $\mathrm{P}<0.05$ were considered to be statistically significant.

\section{RESULTS}

Between 1993 and 2008, a total of 822,865 patients who were admitted for diverticulitis were captured in the NIS sample. This represents an estimated 4,108,726 admissions for diverticulitis nationwide over the course of the study period. The characteristics of patients admitted for diverticulitis, stratified according to hospital volume, are summarized in Table 1 . Data were missing only for patient sex $(n=1051)$, insurance type $(n=2081)$ and admission type $(n=78,069)$. Of note, patients at high-volume hospitals were more likely to be admitted emergently and were more likely to undergo surgical treatment.

\section{Patient mortality according to hospital volume}

Table 2 lists the raw mortality rate, and unadjusted and adjusted OR of mortality according to hospital volume among diverticulitis patients. A total of 80,731 admissions had data missing from the adjusted model, leaving data representing 3,719,102 admissions nationwide. Patients admitted to the lowest-volume hospitals were 1.13 times more likely to die (95\% CI 1.05 to 1.21 ) during hospital admission than patients admitted to higher-volume hospitals. A similar trend was observed in patients in the second lowest quartile of hospital volume (OR 1.12 [95\% CI 1.04 to 1.20$]$ ).

For the sensitivity analysis, restricting the analysis to patients that had diverticulitis listed as their primary diagnosis on admission, a total of 2,638,832 admissions were included in the final adjusted model. The trend was similar to the comparison of hospital volume among all individuals with diverticulitis: patients admitted to the lowest and second lowest quartiles of hospital volume were 1.17 (95\% CI 1.06 to $1.29)$ and 1.16 (95\% CI 1.05 to 1.28$)$ times more likely to die during their admission compared with high-volume hospitals, respectively.

\section{Other predictors of mortality in diverticulitis}

Table 3 lists other factors, aside from hospital volume, that are associated with mortality among diverticulitis patients. The odds of mortality were greater with increased age ( $\geq 60$ versus $<40$ years of age: OR 13.53 [95\% CI 10.28 to 17.82$]$ ), greater burden of comorbidities (OR 1.45 [95\% CI 1.43 to 1.47$]$ ), having a type of health insurance other than a private provider (Medicare versus private: OR $1.55[95 \% \mathrm{CI}$ 1.42 to 1.69$]$ ), being admitted to hospital urgently or emergently versus electively (OR 1.90 [95\% CI 1.76 to 2.06] and OR 2.58 [95\% CI 2.40 to 2.78 ], respectively), undergoing surgical treatment (OR 3.60 [95\% CI 3.42 to 3.78]), having an ICD-9 code corresponding to a more severe disease according to the Hinchey classification (Hinchey I and II versus 0, OR 1.18 [95\% CI 1.11 to 1.27]; Hinchey III and IV versus 0, OR 3.07 [95\% CI 2.82 to 3.34]), and being admitted to a hospital in the Northeastern US. The odds of mortality was decreased among female patients (OR 0.90 [95\% CI 0.87 to 0.94]), individuals of 


\begin{tabular}{|c|c|c|c|c|c|}
\hline & \multirow{2}{*}{$\begin{array}{l}\text { All hospitals } \\
(n=4,108,726)\end{array}$} & \multicolumn{4}{|c|}{ Hospital volume } \\
\hline & & 1st quartile & 2nd quartile & 3rd quartile & 4th quartile \\
\hline \multicolumn{6}{|l|}{$\mathrm{Age}^{*}$, years } \\
\hline$<40$ & $7.0(6.9-7.1)$ & $6.8(6.7-6.9)$ & $7.2(7.1-7.3)$ & $7.1(7.0-7.2)$ & $6.9(6.8-7.0)$ \\
\hline $40-59$ & $38.6(38.4-38.7)$ & $36.5(36.3-36.7)$ & $39.0(38.7-39.1)$ & $39.4(39.2-39.6)$ & $39.4(39.2-39.6)$ \\
\hline$\geq 60$ & $54.4(54.3-54.5)$ & $56.7(56.5-56.9)$ & $53.9(53.7-54.1)$ & $53.4(53.2-53.6)$ & $53.7(53.5-53.9)$ \\
\hline \multicolumn{6}{|l|}{$\operatorname{Sex}^{*}$} \\
\hline Male & $39.2(39.1-39.3)$ & $38.0(37.8-38.2)$ & $39.0(38.8-39.2)$ & $39.6(39.4-39.8)$ & $40.2(39.9-40.4)$ \\
\hline Female & $60.8(60.7-60.9)$ & $62.0(61.8-62.2)$ & $61.0(60.8-61.2)$ & $60.4(60.2-60.6)$ & $59.8(59.6-60.1)$ \\
\hline \multicolumn{6}{|l|}{ Race/ethnicity* } \\
\hline Non-Hispanic white & $63.8(63.7-64.0)$ & $58.5(58.2-58.7)$ & $59.5(59.3-59.7)$ & $65.3(65.1-65.5)$ & $72.2(72.0-72.4)$ \\
\hline Black & $5.4(5.4-5.5)$ & $5.0(4.9-5.1)$ & $5.7(5.6-5.8)$ & $5.0(4.9-5.1)$ & $6.0(5.9-6.1)$ \\
\hline Hispanic & $5.4(5.3-5.4)$ & $5.2(5.1-5.3)$ & $5.4(5.3-5.5)$ & $4.2(4.1-4.3)$ & $6.7(6.6-6.8)$ \\
\hline Unavailable & $25.4(25.3-25.5)$ & $31.4(31.1-31.6)$ & $29.4(29.2-29.6)$ & $25.5(25.3-25.6)$ & $15.1(14.9-15.2)$ \\
\hline Comorbidity score*, mean & $1.78(1.77-1.78)$ & $1.77(1.77-1.78)$ & $1.80(1.79-1.80)$ & $1.77(1.76-1.78)$ & $1.77(1.77-1.78)$ \\
\hline \multicolumn{6}{|l|}{ Health insurance* } \\
\hline Private & $36.5(36.4-36.6)$ & $31.5(31.3-31.7)$ & $36.3(36.1-36.6)$ & $38.8(38.6-39.0)$ & $39.4(39.2-39.63)$ \\
\hline Medicare & $53.7(53.6-53.8)$ & $56.5(56.3-56.8)$ & $53.3(53.1-53.5)$ & $52.3(52.0-52.5)$ & $52.7(52.5-53.0)$ \\
\hline Medicaid & $4.1(4.1-4.2)$ & $5.5(5.4-5.6)$ & $4.3(4.2-4.3)$ & $3.7(3.7-3.8)$ & $3.0(2.9-3.1)$ \\
\hline Self-pay & $3.3(3.3-3.4)$ & $3.9(3.9-4.0)$ & $3.4(3.3-3.5)$ & $3.2(3.2-3.3)$ & $2.7(2.7-2.8)$ \\
\hline Other & $2.3(2.3-2.4)$ & $2.6(2.5-2.7)$ & $2.7(2.6-2.7)$ & $2.0(1.9-2.0)$ & $2.1(2.1-2.2)$ \\
\hline \multicolumn{6}{|l|}{ Admission type* } \\
\hline Elective & $20.5(20.5-20.7)$ & $21.5(21.3-21.7)$ & $20.8(20.7-21.0)$ & $20.1(19.9-20.2)$ & $19.9(19.7-20.1)$ \\
\hline Urgent & $24.1(24.0-24.2)$ & $30.2(30.0-30.4)$ & $25.2(25.0-25.4)$ & $21.6(21.4-21.8)$ & $19.6(19.5-19.9)$ \\
\hline Emergent & $55.3(55.2-55.4)$ & $48.3(48.1-48.6)$ & $54.0(53.7-54.2)$ & $58.4(58.1-58.6)$ & $60.4(30.2-60.6)$ \\
\hline \multicolumn{6}{|l|}{ Hinchey classification* } \\
\hline 0 & $90.3(90.3-90.4)$ & $91.8(91.6-91.9)$ & $90.5(90.4-90.6)$ & $89.9(89.7-90.0)$ & $89.2(89.1-89.4)$ \\
\hline I or II & $8.1(8.0-8.1)$ & $6.7(6.6-6.8)$ & $7.8(7.7-7.9)$ & $8.5(8.4-8.6)$ & $9.2(9.1-9.3)$ \\
\hline III or IV & $1.6(1.6-1.6)$ & $1.5(1.5-1.6)$ & $1.7(1.6-1.7)$ & $1.6(1.6-1.7)$ & $1.6(1.5-1.6)$ \\
\hline \multicolumn{6}{|l|}{ Surgical treatment* } \\
\hline Partial or total colectomy & $20.8(20.7-20.9)$ & $17.4(17.3-17.6)$ & $20.8(20.7-21.0)$ & $22.1(21.9-22.3)$ & $23.0(22.8-23.2)$ \\
\hline
\end{tabular}

Data presented as \% $(95 \% \mathrm{Cl})$ unless otherwise indicated. ${ }^{*} P<0.0001$

TABLE 2

Mortality rate, unadjusted and adjusted OR of mortality of diverticulitis patients according to hospital volume quartile

\begin{tabular}{|c|c|c|c|}
\hline Hospital volume & $\begin{array}{c}\text { Mortality rate, } \\
\%(95 \% \mathrm{Cl})\end{array}$ & $\begin{array}{l}\text { Unadjusted* } \\
\text { OR }(95 \% \mathrm{Cl})\end{array}$ & $\begin{array}{c}\text { Adjusted }{ }^{\dagger} \\
\text { OR }(95 \% \mathrm{Cl})\end{array}$ \\
\hline 1st quartile (lowest) & $1.80(1.74-1.86)$ & $0.94(0.90-0.99)$ & $1.13(1.05-1.21)$ \\
\hline 2nd quartile & $1.90(1.83-1.96)$ & $1.00(0.95-1.04)$ & $1.12(1.04-1.20)$ \\
\hline 3rd quartile & $1.89(1.83-1.95)$ & $0.99(0.95-1.04)$ & $1.06(0.98-1.14)$ \\
\hline 4th quartile (highest) & $1.90(1.83-1.95)$ & 1.00 & 1.00 \\
\hline
\end{tabular}

*Unadjusted analysis does not account for the effect of clustering; ${ }^{\dagger}$ Adjusted for age, sex, race, comorbidity index score, health insurance, admission type, Hinchey classification, calendar year of admission, colectomy and effect of clustering

Hispanic background versus non-Hispanic white (OR 0.85 [95\% CI 0.77 to 0.94$]$ ), and with admission to a hospital later in the study period (OR 0.96 [95\% CI 0.95 to 0.96] per year).

\section{DISCUSSION}

The present population-based study using data representing $>4$ million hospital admissions for diverticulitis in the US highlights a few important associations. First, patients admitted to low-volume hospitals had a greater odds for mortality compared with patients admitted to hospitals that encountered a higher caseload of diverticulitis. Second, increasing age and comorbidity burden, being admitted emergently, increasing disease severity according to the Hinchey classification, undergoing surgery, receiving health insurance from a source other than a private provider, and being admitted to a hospital in the Northeastern US were all associated with an increased odds of mortality.

Although the present study was the first to examine the relationship between hospital volume and mortality in diverticulitis patients, many of the findings are consistent with previous research examining the effect of hospital volume in other patient populations. Previous studies have found an increased mortality risk among patients treated in lower-volume hospitals for inflammatory bowel disease (12), as well as increased mortality risk among patients undergoing surgery for inflammatory bowel disease in low-volume hospitals $(11,13,19)$. Similar to findings in Etzioni et al (20), we also demonstrated an increased risk for mortality among patients who were either older, undergoing surgery, or admitted emergently or urgently, as well as a temporal trend of decreased mortality over the course of the study period. Our finding of a greater risk for mortality among diverticulitis patients with insurance coverage other than a private provider has also been previously demonstrated (21,22). Although Ho et al (22) also found no increased risk for mortality among black patients compared with non-Hispanic white patients, others studies have demonstrated an increased risk for mortality among African Americans $(21,23,24)$. Furthermore, to our knowledge, the present study was the first to use ICD-9-CM diagnostic codes in an administrative database to stratify diverticulitis patients according to disease severity according to the Hinchey classification. 
TABLE 3

Demographic and hospital-level predictors of in-hospital mortality in patients hospitalized for diverticulitis

\begin{tabular}{|c|c|c|c|}
\hline Characteristic & Mortality rate, $\%(95 \% \mathrm{Cl})$ & Unadjusted OR $(95 \% \mathrm{Cl})^{*}$ & Adjusted OR $(95 \% \mathrm{Cl})^{\dagger}$ \\
\hline \multicolumn{4}{|l|}{ Age, years } \\
\hline$<40$ & $0.12(0.09-0.15)$ & 1.00 & 1.00 \\
\hline $40-59$ & $0.49(0.46-0.51)$ & $4.19(3.25-5.40)$ & $3.48(2.66-4.55)$ \\
\hline$\geq 60$ & $3.07(3.02-3.13)$ & $26.99(21.02-36.64)$ & $13.53(10.28-17.82)$ \\
\hline \multicolumn{4}{|l|}{ Sex } \\
\hline Male & $1.63(1.59-1.68)$ & 1.00 & 1.00 \\
\hline Female & $2.03(1.99-2.07)$ & $1.25(1.21-1.29)$ & $0.90(0.87-0.94)$ \\
\hline \multicolumn{4}{|l|}{ Race/ethnicity } \\
\hline Non-Hispanic white & 2.03 (1.99-2.07) & 1.00 & 1.00 \\
\hline Black & $1.93(1.80-2.06)$ & $0.95(0.88-1.02)$ & $1.00(0.91-1.09)$ \\
\hline Hispanic & $1.28(1.18-1.39)$ & $0.63(0.58-0.68)$ & $0.85(0.77-0.94)$ \\
\hline Other/unavailable & $1.59(1.53-1.64)$ & $0.78(0.75-0.81)$ & $0.95(0.91-1.01)$ \\
\hline Comorbidity score ${ }^{\ddagger}$ & $0.65(0.62-0.68)$ & $1.45(1.43-1.47)$ & $1.45(1.43-1.47)$ \\
\hline \multicolumn{4}{|l|}{ Health insurance } \\
\hline Private & $0.51(0.49-0.54)$ & 1.00 & 1.00 \\
\hline Medicare & $2.97(2.92-3.02)$ & $5.94(5.62-6.27)$ & $1.55(1.42-1.69)$ \\
\hline Medicaid & $1.11(1.00-1.23)$ & $2.19(1.95-2.45)$ & $1.90(1.66-2.19)$ \\
\hline Self-pay & $0.58(0.49-0.67)$ & $1.14(0.97-1.34)$ & $1.44(1.19-1.74)$ \\
\hline Other & $1.00(0.85-1.14)$ & $1.95(1.67-2.29)$ & $1.93(1.62-2.29)$ \\
\hline \multicolumn{4}{|l|}{ Admission type } \\
\hline Elective & $1.41(1.37-1.46)$ & 1.00 & 1.00 \\
\hline Urgent & $1.76(1.69-1.82)$ & $1.25(1.19-1.31)$ & $1.90(1.76-2.06)$ \\
\hline Emergent & $2.17(2.13-2.22)$ & $1.55(1.49-1.61)$ & $2.58(2.40-2.78)$ \\
\hline \multicolumn{4}{|l|}{ Surgery } \\
\hline No surgical treatment & $1.43(1.40-1.46)$ & 1.00 & 1.00 \\
\hline Partial or total colectomy & $3.54(3.45-3.63)$ & $2.53(2.45-2.61)$ & $3.60(3.42-3.78)$ \\
\hline \multicolumn{4}{|l|}{ Hinchey clasification } \\
\hline 0 & $1.70(1.67-1.73)$ & 1.00 & 1.00 \\
\hline I or II & $2.40(2.28-2.52)$ & $1.42(1.35-1.50)$ & $1.18(1.11-1.26)$ \\
\hline III or IV & $8.63(8.15-9.11)$ & $5.46(5.12-5.82)$ & $3.07(2.82-3.34)$ \\
\hline \multicolumn{4}{|l|}{ Region } \\
\hline Northeast & 2.12 (2.05-2.19) & 1.00 & 1.00 \\
\hline Midwest & $1.74(1.69-1.80)$ & $0.82(0.78-0.86)$ & $0.82(0.76-0.88)$ \\
\hline South & $1.74(1.69-1.78)$ & $0.82(0.78-0.85)$ & $0.79(0.74-0.84)$ \\
\hline West & $2.05(1.97-2.13)$ & $0.97(0.92-1.02)$ & $0.83(0.76-0.91)$ \\
\hline \multicolumn{4}{|l|}{ Quarter of admission } \\
\hline January to March & $1.90(1.85-1.95)$ & 1.00 & 1.00 \\
\hline April to June & $1.81(1.75-1.87)$ & $0.95(0.91-1.00)$ & $0.96(0.92-1.02)$ \\
\hline July to September & $1.78(1.72-1.84)$ & $0.94(0.90-0.98)$ & $0.96(0.91-1.01)$ \\
\hline October to December & $1.99(1.92-2.05)$ & $1.05(1.01-1.10)$ & $1.07(1.01-1.13)$ \\
\hline Calendar year & N/A & $0.96(0.96-0.97)$ & $0.96(0.95-0.96)$ \\
\hline
\end{tabular}

*Unadjusted analysis does not account for effect of clustering; ${ }^{\dagger}$ Adjusted for age, sex, race, comorbidity index score, health insurance, admission type, Hinchey classification, calendar year of admission, colectomy and effect of clustering; $¥$ Mortality rate, unadjusted OR and adjusted OR for each additional point on comorbidity score. N/A Not applicable

There are a few different explanations that could account for the greater mortality risk in low-volume centres as opposed to high-volume hospitals. In high-volume hospitals, physicians may be more familiar with therapeutic regimens, more likely to recognize early and potentially serious complications, and may recognize the need for surgical intervention and operate earlier (11). High-volume hospitals may also be able to provide more comprehensive intensive care, allow for more multidisciplinary support, and employ more experienced allied health care professionals and nursing staff (12). Hospital volume may influence outcomes for patients undergoing surgery in several ways, including surgeon experience, patient selection for operative treatment and postoperative care (13).

It should be noted that our adjusted risk estimates demonstrated a high risk for mortality among patients in low-volume hospitals, despite the fact that the raw mortality rates were higher among patients in high-volume centres compared with low-volume hospitals. However, high-volume centres also had a greater proportion of patients admitted emergently, who underwent surgery and with greater disease severity, all of which are associated with an increased risk for mortality and were included as covariates in the adjusted model. Moreover, the association of a higher risk for mortality among patients in lower-volume hospitals was also demonstrated when restricting analyses solely to patients who had a primary diagnosis of diverticulitis.

There were several limitations to the present study. As is the case with all studies using administrative databases, the accuracy of the data and the potential for misclassification of exposure and outcome are potential issues (25), although the outcome of in-hospital mortality is relatively robust. Additionally, we attempted to control for disease 
severity by using the Hinchey classification and patients' presentation on admission (such as urgent or emergent), the latter of which is also prone to misclassification. Due to the limitations of ICD-9-CM coding, we could only assign patients into strata of Hinchey classification (despite there being five levels of the classification). This method of adjustment has not been previously validated and is, thus, a limitation of our attempt to adjust for severity of diverticulitis. Also, because the NIS extracts information from hospital discharge abstracts, it is exceedingly difficult to accumulate long-term data in terms of outcomes postdischarge. Furthermore, because NIS data are deidentified, multiple admissions by the same individual for diverticulitis could not be accounted for in the data analysis. Despite the limitations of NIS data, they do allow for a national determination of risk factors and aspects of health care delivery associated with better outcomes.

\section{CONCLUSION}

Using a nationwide database of hospital admissions, we established that diverticulitis patients admitted to hospitals that encounter a low volume of diverticulitis cases have an increased risk for death compared with those admitted to high-volume centres. The present study highlights the need for further research into determining which mechanisms, practices and models of care are directly responsible for better outcomes in the treatment of diverticulitis.

\section{REFERENCES}

1. DeFrances CJ, Lucas CA, Buie VC, Golosinskiy A. 2006 National Hospital Discharge Survey. Natl Health Stat Report 2008;5:1-20.

2. Nguyen GC, Sam J, Anand N. Epidemiological trends and geographic variation in hospital admissions for diverticulitis in the United States. World J Gastroenterol 2011;17:1600-5.

3. Parks TG. Natural history of diverticular disease of the colon. Clin Gastroenterol 1975;4:53-69.

4. Kyle J, Adesola AO, Tinckler LF, de Beaux J. Incidence of diverticulitis. Scand J Gastroenterol 1967;2:77-80.

5. Lopez DE, Brown CV. Diverticulitis: The most common colon emergency for the acute care surgeon. Scand J Surg 2010;99:86-9.

6. Waugh JM, Walt AJ. Current trends in the surgical treatment of diverticulitis of the sigmoid colon. Surg Clin North Am 1962;42:1267-76.

7. Rafferty J, Shellito P, Hyman NH, et al. Practice parameters for sigmoid diverticulitis. Dis Colon Rectum 2006;49:939-44.

8. Telem DA, Buch KE, Nguyen SQ, et al. Current recommendations on diagnosis and management of right-sided diverticulitis. Gastroenterol Res Pract 2009;2009:359485.

9. Parks TG, Connell AM. The outcome in 455 patients admitted for treatment of diverticular disease of the colon. Br J Surg 1970;57:775-8.

10. Peppas G, Bliziotis IA, Oikonomaki D, Falagas ME. Outcomes after medical and surgical treatment of diverticulitis: A systematic review of the available evidence. J Gastroenterol Hepatol 2007;22:1360-8.

11. Ananthakrishnan AN, McGinley EL, Binion DG. Does it matter where you are hospitalized for inflammatory bowel disease? A nationwide analysis of hospital volume. Am J Gastroenterol 2008;103:2789-98.

12. Nguyen GC, Steinhart AH. Nationwide patterns of hospitalizations to centers with high volume of admissions for inflammatory bowel disease and their impact on mortality. Inflamm Bowel Dis 2008;14:1688-94.

13. Kaplan GG, McCarthy EP, Ayanian JZ, et al. Impact of hospital volume on postoperative morbidity and mortality following a colectomy for ulcerative colitis. Gastroenterology 2008;134:680-7.

14. Karanicolas PJ, Dubois L, Colquhoun PH, et al. The more the better?: The impact of surgeon and hospital volume on in-hospital mortality following colorectal resection. Ann Surg 2009;249:954-9.
ACKNOWLEDGEMENTS: The authors acknowledge the intellectual contribution to the manuscript by Linnette Yen at Shire, Wayne, PA, USA. Dr Kaplan and Dr Dixon are supported by New Investigator awards from the Canadian Institute of Health Research and Population Health Investigator awards from Alberta-Innovates Health Solutions. Shire Development LLC was a source of funding for this study and reviewed the manuscript.

DISCLOSURES: Shire Development LLC, Wayne, PA, USA provided funding for the study. Gilaad Kaplan has served as a speaker and received honoraria from Merck, Schering-Plough, Janssen, Abbott and UCB Pharma. He has participated in advisory board meetings and received honoraria from Abbott, Merck, Schering-Plough, Janssen, Shire and UCB Pharma. Dr Kaplan has received research support from Merck, Abbott and Shire. Dr Kaplan and Dr Dixon are supported by New Investigator awards from the Canadian Institute of Health Research and Population Health Investigator awards from Alberta-Innovates Health Solutions. Samuel Schaffer is an employee of Shire. The remaining authors have no financial disclosures or conflicts of interest to declare.

CONTRIBUTIONS: Dr Gilaad Kaplan and Michael Diamant were involved in all aspects of the study, including conception, design, data collection, analysis and writing. They had full access to all of the data in the study and take responsibility for the integrity of the data and the accuracy of the data analysis. All other authors contributed substantially to data interpretation, study write-up and final approval of the version to be published.

15. Weber WP, Guller U, Jain NB, et al. Impact of surgeon and hospital caseload on the likelihood of performing laparoscopic vs open sigmoid resection for diverticular disease: A study based on 55,949 patients. Arch Surg 2007;142:253-9.

16. Siddiqui MR, Sajid MS, Khatri K, et al. Elective open versus laparoscopic sigmoid colectomy for diverticular disease: A metaanalysis with the Sigma trial. World J Surg 2010;34:2883-901.

17. Hinchey, EJ, Schaal, PG, Richards GK. Treatment of perforated diverticular disease of the colon. Adv Surg 1978;12:85-109.

18. Elixhauser A, Steiner C, Harris DR, Coffey RM. Comorbidity measures for use with administrative data. Med Care 1998;36:8-27.

19. Kaplan GG, Hubbard J, Panaccione R, et al. The risk of comorbidities on postoperative outcomes in inflammatory bowel disease patients. Arch Surg 2011;146:959-64.

20. Etzioni DA, Mack TM, Beart RW Jr, Kaiser AM. Diverticulitis in the United States: 1998-2005: Changing patterns of disease and treatment. Ann Surg 2009;249:210-7.

21. Lidor AO, Gearhart SL, Wu AW, Chang DC. Effect of race and insurance status on presentation, treatment, and mortality in patients undergoing surgery for diverticulitis. Arch Surg 2008;143:1160-5.

22. Ho VP, Nash GM, Feldman EN, et al. Insurance but not race is associated with diverticulitis mortality in a statewide database. Dis Colon Rectum 2011;54:559-65.

23. Alavi K, Cervera-Servin JA, Sturrock PR, et al. Racial differences in short-term surgical outcomes following surgery for diverticulitis. J Gastrointest Surg 2012;16:613-21.

24. Schneider EB, Haider A, Sheer AJ, et al. Differential association of race with treatment and outcomes in Medicare patients undergoing diverticulitis surgery. Arch Surg 2011;146:1272-6.

25. Molodecky NA, Panaccione R, Ghosh S, Barkema HW, Kaplan GG. Challenges associated with identifying the environmental determinants of the inflammatory bowel diseases. Inflamm Bowel Dis 2011;17:1792-9. 


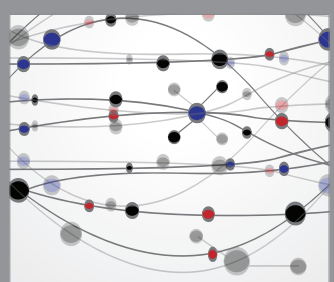

The Scientific World Journal
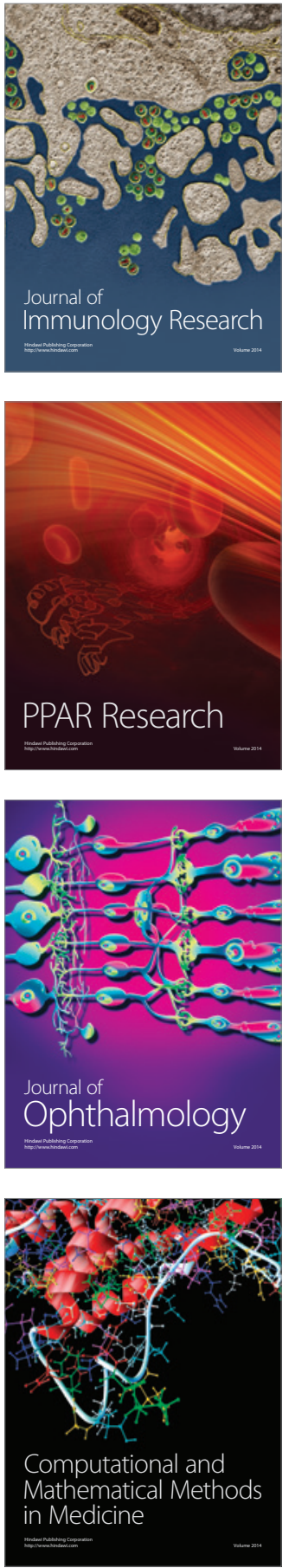

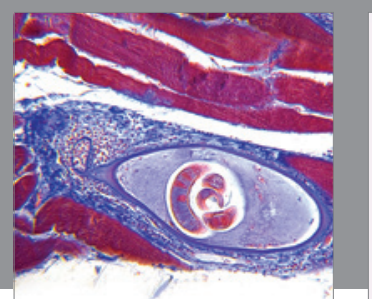

Gastroenterology Research and Practice

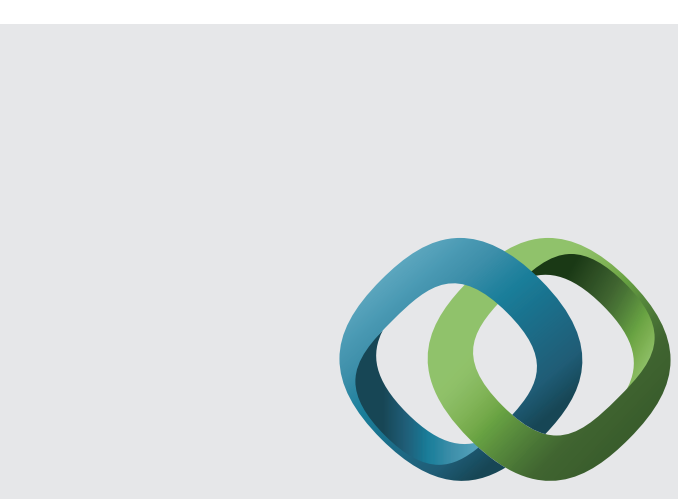

\section{Hindawi}

Submit your manuscripts at

http://www.hindawi.com
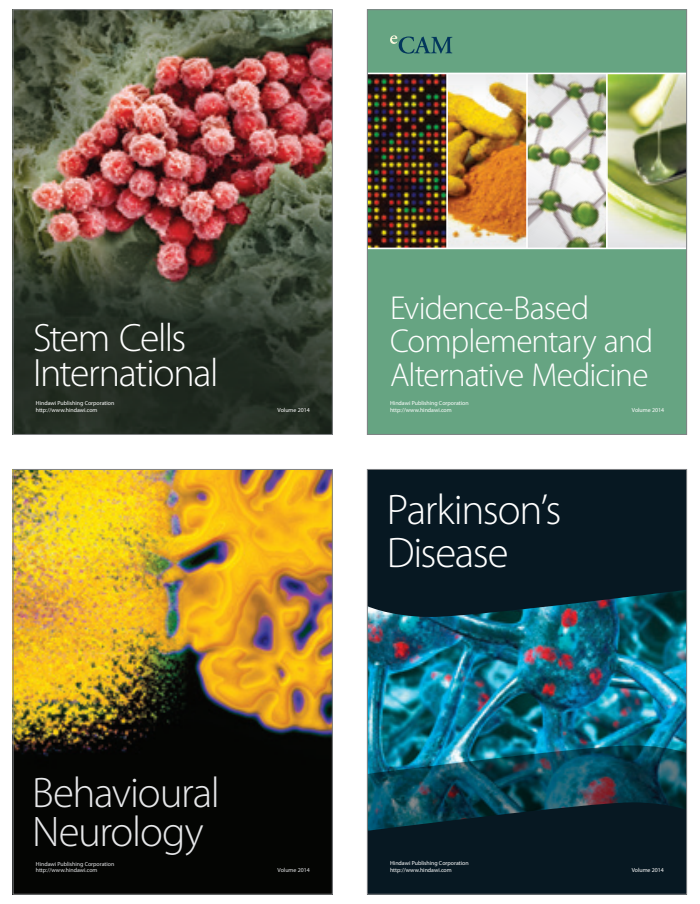
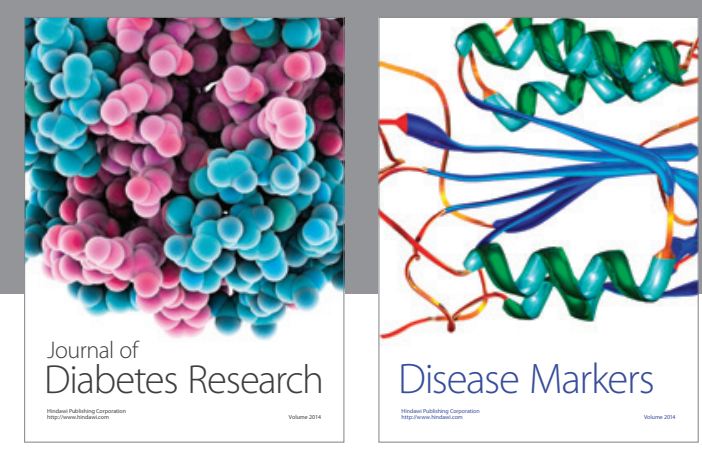

Disease Markers
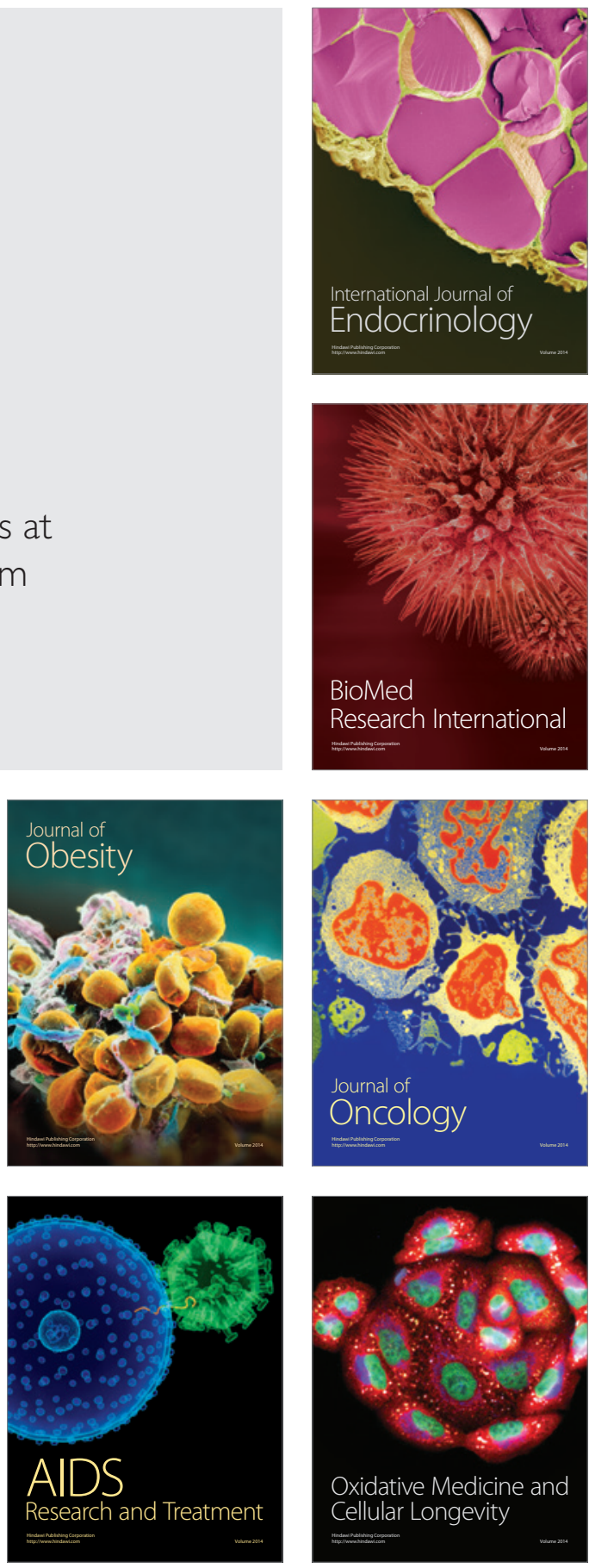